\title{
FORMULATION AND INVESTIGATION OF POLYMERIC MULTIPLE UNIT PELLET SYSTEMS CONSISTING OF SUSTAINED RELEASE GLIMEPIRIDE AND IMMEDIATE RELEASE ATORVASTATIN CALCIUM
}

\section{BHARAT BIJAPUR ${ }^{1}$, GOWDA DV ${ }^{1 *}$, VISHAL GUPTA N ${ }^{1}$, SHAILESH THIRUMALESHWAR ${ }^{1}$, PRAVEEN SIVADASU ${ }^{1}$, MANJUNATH $\mathbf{M}^{2}$}

${ }^{1}$ Department of Pharmaceutics, JSS College of Pharmacy, Sri Shivarathreeshwara Nagara, JSS Academy of Higher Education and Research, JSS Medical Institutions Campus, Sri Shivarathreeshwara Nagara, Mysuru, Karnataka, India. ${ }^{2}$ Department of Pharmaceutics, Farooqia College of Pharmacy, Mysuru, Karnataka, India. Email: dvgowda@jssuni.edu.in

Received: 13 February 2019, Revised and Accepted: 30 March 2019

ABSTRACT

Objective: The objective of the present work was to develop novel fixed-dose combinations (FDCs) for improvement of glucose tolerance in type II diabetes mellitus patients associated with dyslipidemia.

Methods: Multiple unit pellet systems (MUPSs) consisting of sustained release (SR) glimepiride and immediate release atorvastatin calcium pellets were formulated. The SR glimepiride pellets were prepared using a combination of locust bean gum and gum ghatti/guar gum. Similarly, the immediate release of atorvastatin calcium pellets was prepared using locust bean gum suspension as a binder.

Results: The formulated pellets were characterized using Fourier transform infrared spectroscopy (FTIR) and Differential scanning calorimetry (DSC). Further, surface morphology of the formulated pellets was done by scanning electron microscopy (SEM). FT-IR and DSC studies suggested that there were no chemical interactions between the drug and natural polymers. SEM studies revealed that formulated pellets were in spherical shape. Based on in vitro evaluation, the SR glimepiride formulation developed using a combination of $2 \%$ locust bean gum and $2.5 \%$ gum ghatti polymers sustained the release of the drug up to $12 \mathrm{~h}$. Similarly, the immediate release atorvastatin calcium formulation containing $1 \%$ w/w locust bean gum suspension as a binder and 7\% croscarmellose sodium showed fast disintegration of pellets. The in vivo studies in albino Wistar rat revealed that there was an improvement in bioavailability of the drugs. Stability studies showed that there were no significant changes in the drug content and physical appearance of the prepared SR glimepiride and immediate release atorvastatin pellet formulations.

Conclusion: Thus, the formulated FDC as MUPS can be used as an alternative approach for treating diabetes mellitus-induced dyslipidemia.

Keywords: Multiple unit pellet systems, Type II diabetes mellitus, Dyslipidemia glimepiride, Atorvastatin calcium.

(C) 2019 The Authors. Published by Innovare Academic Sciences Pvt Ltd. This is an open access article under the CC BY license (http://creativecommons. org/licenses/by/4. 0/) DOI: http://dx.doi.org/10.22159/ajpcr.2019.v12i5.32583

\section{INTRODUCTION}

Diabetes mellitus (DM) is a heterogeneous metabolic disorder, characterized by impaired metabolism of glucose, lipids, and proteins. This is due to deficiency of insulin secretion or resistance to insulin action or both. If it is left untreated, it may lead to many complications such as diabetic ketoacidosis, retinopathy, neuropathy, nephropathy, cardiovascular complications, and ulceration or it may lead to death [1]. DM can be classified into two types. Type I DM is also known as insulindependent DM and type II DM is known as non-insulin-dependent diabetes mellitus. Type II DM is very common compared to type I DM and estimated that more than 200 million people are suffering from diabetes [2].

In recent times, multiple unit pellet systems (MUPS) have grabbed the attention of pharmaceutical industries (API) among other formulations to treat diabetes-induced dyslipidemia as they deliver both immediate release and sustained release (SR) formulations in a single dosage. It is more advantageous when compared to other formulations due to its unique mechanical and physical properties [3]. Pellets can be delivered as both coated and uncoated form based on the release profile of the drug [4].

Glimepiride is the third-generation sulfonylurea. Glimepiride reduces the blood sugar level by stimulating the release of insulin by pancreatic beta-cells and increasing activity of intracellular insulin receptor. Due to its smaller biological half-life $(5 \mathrm{~h})$, it requires frequent administration. To reduce the dosing frequency, SR glimepiride formulations should be formulated to maintain the blood glucose levels [5].
Atorvastatin belongs to statin family. Atorvastatin is a synthetic lipidlowering drug. Atorvastatin is a selective, competitive inhibitor of HMG-CoA reductase. HMG-CoA reductase catalyzes the reduction of 3-hydroxy-3-methylglutaryl-coenzyme A to mevalonate. It also inhibits the task associated with cardiovascular diseases. Statins shall also reduce the blood levels of triglycerides and slightly increases the levels of high-density lipoprotein-cholesterol [6].

Here, in the current research work, a basic pellet formulation containing drugs and natural gums was formulated by employing the spheronization technique to modify the drug release using various concentrations to improve glucose tolerance in diabetes.

\section{MATERIALS AND METHODS}

Materials

Glimepiride and atorvastatin were purchased from Micro Labs, Bengaluru. Locust bean gum, gum ghatti, and guar gum were purchased from Loba Chemie, Mumbai. All other ingredients used were of analytical grade.

\section{Methods}

Preparation of drug-loaded SR glimepiride pellets

The preparation of glimepiride pellets was carried out using the extrusion/ spheronization process. Extrusion spheronization process involves four 
steps as moistening the powder mixture, forming cylindrical shaped agglomerate through extrusion, breaking and rounding the extrudates to round pellets through spheronization, and drying the finished product. A uniform dry powder mixture (batch size $100 \mathrm{~g}$ ) containing glimepiride, microcrystalline cellulose (MCC) (AvicelPH101), locust bean gum, and gum ghatti/guar gum in different concentrations was obtained by mixing in polyethylene bag for 10-15 min as shown in Table 1. The above mixture was then granulated using water and isopropyl alcohol in 5:2 ratio as granulation fluid. Then, the wet granulation mixture was extruded, and the extrudates were then immediately spheronized to yield the spherical pellets. The pellets were dried in a hot-air oven at $40^{\circ} \mathrm{C}$ for $10-12 \mathrm{~h}$. The dried pellets were then filled and stored in screw-capped, high-density polyethylene bottles [7].

\section{Preparation of drug-loaded immediate release atorvastatin calcium} pellets

Similar to above glimepiride pellets formulation, the preparation of atorvastatin pellets was carried out using the extrusion/ spheronization process. Uniform dry powder mixture (batch size 100 g) containing atorvastatin calcium and excipients such as MCC (AvicelPH101), sodium starch glycolate/croscarmellose sodium, sodium lauryl sulfate (SLS), and sodium bicarbonate was obtained in different concentrations by mixing it in a polyethylene bag for 1015 min as shown in Table 2. The mixture was then granulated by using $1 \% \mathrm{w} / \mathrm{w}$ locust bean gum/PVPK-30 in water as granulation fluid. Then, the wet granulation mixture was extruded, and the extrudates were then immediately spheronized to yield the spherical pellets. The pellets were dried in a hot-air oven at $40^{\circ} \mathrm{C}$ for $10-12 \mathrm{~h}$. The dried pellets were then filled and stored in screw-capped, high-density polyethylene bottles.

\section{Characterization}

Fourier transform infrared (FT-IR) studies of glimepiride and atorvastatin calcium

To determine the compatibility of the drug and polymer, FT-IR spectroscopy was used. Results were recorded using FT-IR (8400S, Shimadzu Corporation, Japan). API dispersed with KBR in a mortar, the material is triturated into a fine powder with the help of compression gauge, and the powder has been compressed in a holder. Moreover, the pressure of 5 ton is applied for $5 \mathrm{~min}$, the pellet was placed in a light path, and the results were recorded [6].

\section{Differential Scanning Calorimetry (DSC)}

All DSC studies of pure drug and prepared formulations were carried out on Shimadzu Thermal Analyzer (TA-60WS). A few milligrams of the sample were entirely sealed into aluminum pans and heated under a nitrogen atmosphere with the heating rate of $10^{\circ} \mathrm{C} / \mathrm{min}$ [8].

\section{Solubility}

Solubility studies of glimepiride and atorvastatin calcium were carried out using distilled water. Glimepiride and atorvastatin calcium were taken in vials containing distilled water. The vials were subjected to stirring for $24 \mathrm{~h}$ on a magnetic stirrer, and the obtained solution was filtered and the filtrate was estimated spectrophotometrically at

Table 1: Formulation chart of sustained release glimepiride pellets

\begin{tabular}{|c|c|c|c|c|c|c|}
\hline \multicolumn{6}{|c|}{ Ingredient concentration $(\% \mathrm{w} / \mathrm{w})$} & \multirow{2}{*}{$\begin{array}{l}\text { Wetting agent volume } \\
\text { (water:IPA) }(5: 2)(\mathrm{mL} / \mathrm{g})\end{array}$} \\
\hline Formulation code & Glimepiride & MCC & Locust bean gum & Gum ghatti & Gaur gum & \\
\hline BD-1 & 2.5 & 96.5 & 1 & - & - & 0.80 \\
\hline BD-2 & 2.5 & 95.5 & 2 & - & - & 0.77 \\
\hline BD-3 & 2.5 & 94.5 & 3 & - & - & 0.77 \\
\hline BD-4 & 2.5 & 95.0 & 2 & 0.5 & - & 0.70 \\
\hline BD-5 & 2.5 & 94.5 & 2 & 1 & - & 0.77 \\
\hline BD-6 & 2.5 & 94.0 & 2 & 1.5 & - & 0.84 \\
\hline BD-7 & 2.5 & 93.5 & 2 & 2 & - & 0.84 \\
\hline BD-8 & 2.5 & 93.0 & 2 & 2.5 & - & 0.80 \\
\hline BD-9 & 2.5 & 95.0 & 2 & - & 0.5 & 0.74 \\
\hline BD-10 & 2.5 & 94.5 & 2 & - & 1 & 0.74 \\
\hline BD-11 & 2.5 & 94.0 & 2 & - & 1.5 & 0.80 \\
\hline BD-12 & 2.5 & 93.5 & 2 & - & 2 & 0.74 \\
\hline BD-13 & 2.5 & 93.0 & 2 & - & 2.5 & 0.80 \\
\hline
\end{tabular}

MCC: Microcrystalline cellulose

Table 2: Formulation chart immediate release atorvastatin calcium pellets

\begin{tabular}{|c|c|c|c|c|c|c|}
\hline \multicolumn{7}{|c|}{ Ingredient concentration $(\% \mathrm{w} / \mathrm{w})$} \\
\hline Formulation & Atorvastatin calcium & MCC & SSG & CCS & Sodium bicarbonate & SLS \\
\hline FR-1 & 4 & 92 & 1 & - & 2 & 1 \\
\hline FR-3 & 4 & 90 & 3 & - & 2 & 1 \\
\hline FR-4 & 4 & 89 & 4 & - & 2 & 1 \\
\hline FR-5 & 4 & 88 & 5 & - & 2 & 1 \\
\hline FR-6 & 4 & 87 & 6 & - & 2 & 1 \\
\hline FR-7 & 4 & 86 & 7 & - & 2 & 1 \\
\hline FR-8 & 4 & 92 & - & 1 & 2 & 1 \\
\hline FR-9 & 4 & 91 & - & 2 & 2 & 1 \\
\hline FR-10 & 4 & 90 & - & 3 & 2 & 1 \\
\hline FR-11 & 4 & 89 & - & 4 & 2 & 1 \\
\hline FR-12 & 4 & 88 & - & 5 & 2 & 1 \\
\hline FR-13 & 4 & 87 & - & 6 & 2 & 1 \\
\hline FR-14 & 4 & 86 & - & 7 & 2 & 1 \\
\hline FR-15 & 4 & 86 & - & 7 & 2 & 1 \\
\hline
\end{tabular}

SLS: Sodium lauryl sulfate, MCC: Microcrystalline cellulose 
wavelengths of $249 \mathrm{~nm}$ for glimepiride and $246 \mathrm{~nm}$ for atorvastatin calcium, respectively [9].

\section{pH of gums}

The accurate measurement of $\mathrm{pH}$ was done using probe $\mathrm{pH}$ meter. The measurement was done by submerging the probe in the liquid until a reading is registered by the meter [9].

\section{Micromeritic properties}

Micromeritic properties for both glimepiride and atorvastatin calcium such as angle of repose, Carr's index as well as tapped density were determined. The tapped density was determined using a tapped density tester, in which the glass cylinder was tapped 1000 times. The angle of repose is the most widely used method to check the flowability of pellets, which is done by measuring the height of the heap [10]

\section{Scanning electron microscopy (SEM)}

SEM photographs were taken with a SEM at the required magnification. The photographs were observed for morphological characteristics and to confirm spherical nature of the pellets. SEM was performed using Hitachi and SEM at $5 \mathrm{kV}$ having different magnifications using Hitachi Noran System 7 manufactured by Thermo Fisher Scientific [10].

\section{Evaluation of prepared pellets}

\section{Friability}

Friability of pellets was determined by roche friabilator. $10 \mathrm{~g}$ of pellets were subjected to testing at $25 \mathrm{rpm}$ for $4 \mathrm{~min}$. Samples were sieved and the pellets retained on the sieve were weighed, and percentage friability was calculated from the difference in the weight of the pellets before and after friability.

\section{Percentage yield}

The yield of pellets was determined by the whole weight of pellets formed against the combined weights of drug, polymer, and other excipients.

\section{Drug loading and entrapment efficiency}

A specific amount of crushed pellets was suspended into freshly prepared $100 \mathrm{ml}$ phosphate buffer of $\mathrm{pH} 6.8$ with $0.5 \% \mathrm{w} / \mathrm{v}$ sodium lauryl sulfate with constant shaking at room temperature for $24 \mathrm{~h}$. The final solutions were filtered, and the drug content and entrapment efficiency were measured for each formulation at specified wavelengths.

\section{Pellet disintegration test}

A tablet disintegration tester with a diameter of $10 \mathrm{~mm}$, length of $15 \mathrm{~mm}$ and with a $710 \mathrm{~mm}$ mesh was used to estimate the disintegration time of the formulated pellets. After filling the tubes with pellets in each tube, they were inserted in the standard tablet disintegration tester and the temperature was maintained at $37^{\circ} \mathrm{C}$, and the results were expressed in seconds [11]

\section{In vitro dissolution studies}

To study the in vitro dissolution profile, glimepiride pellets equivalent to $2.67 \mathrm{mg}$ and atorvastatin calcium pellets equivalent to $10 \mathrm{mg}$ were mixed together in fixed dose combination (FDC) and filled into the hard gelatin capsule. Electrolab USP dissolution testing apparatus I (basket type) was used to evaluate the rate of drug release from formulated pellets. A freshly prepared phosphate buffer of $\mathrm{pH} 6.8$ with $0.5 \% \mathrm{w} / \mathrm{v}$ SLS $(900 \mathrm{ml})$ was used as dissolution medium at $37 \pm 1^{\circ} \mathrm{C}$, rotated at $75 \mathrm{rpm}$. Withdrawn samples at pre-set time intervals were replaced with equal amounts of fresh buffer and samples were analyzed at the specified wavelengths [12].

\section{In vivo studies}

The study was conducted in accordance with the principles of laboratory animal care and was approved by the animal ethics committee.

\section{Study design}

A total of 12 albino Wistar rats of either sex weighing around 230-260 g were divided into two groups of six, namely control and test. For oral administration, optimized SR glimepiride (formulation BD-8) and immediate release atorvastatin calcium (formulation FR-14) pellet formulations were mixed in fixed dose ratio and administered to rats. The dose administered was $5 \mathrm{mg} / \mathrm{kg}$ of glimepiride and $25 \mathrm{mg} / \mathrm{kg}$ of atorvastatin calcium. Pure drugs, i.e., glimepiride and atorvastatin calcium were mixed in equivalent doses and dissolved in water (control) and administered orally using stomach sonde needle. Blood samples $(0.3 \mathrm{ml})$ were obtained immediately before and after dosing at predetermined time intervals from the jugular vein. Samples were collected in heparinized tubes and were centrifuged for $5 \mathrm{~min}$ at 10,000 rpm at $4^{\circ} \mathrm{C}$. Plasma was separated and stored at $-50^{\circ} \mathrm{C}$ for further analysis. Drug concentration in plasma samples (test and control) withdrawn at various time intervals was determined.

\section{Pharmacokinetic and statistical analysis}

The maximum plasma concentration $\left(\mathrm{C}_{\max }\right)$ and the time to reach peak plasma concentration $\left(\mathrm{T}_{\max }\right)$ were obtained directly from the concentration-time data. The elimination rate constant (K5) was obtained from the slope of the linear part of the elimination phase. The elimination half-life $\left(\mathrm{t}_{1 / 2}\right)$ was calculated from $0.693 / \mathrm{KE}$, while the area under the curve to the last measurable concentration (AUCM) was calculated by the linear trapezoidal rule. The area under the curve extrapolated to infinity (AUCMO) was obtained as AUCQ4+Ct/KE. The significance of the differences observed for the mean pharmacokinetic parameters of the test (FDC of optimized glimepiride and atorvastatin calcium pellets) and the combination of their respective pure drugs (control) was evaluated using Student's t-test at a significance level of $\mathrm{p}<0.05$ [13].

\section{Stability studies}

The optimized batches of SR Glimepiride and immediate release Atorvastatin calcium pellet formulations were mixed in FDC and filled into capsules, and finally, the capsules were placed in an aluminum pouch and heat-sealed. The packed formulation was subjected to stability studies at storage conditions such as $25 \pm 2^{\circ} \mathrm{C} / 60 \pm 5 \% \mathrm{RH}$, $30 \pm 2^{\circ} \mathrm{C} / 65 \pm 5 \% \mathrm{RH}$, and $40 \pm 2^{\circ} \mathrm{C} / 75 \pm 5 \%$ RH for 6 months. Samples were withdrawn on 0 day, 3 months, and 6 months and evaluated for their physical appearance, friability, and drug content $[14,15]$.

\section{RESULTS AND DISCUSSION}

FT-IR studies of glimepiride

The position of the peak in FT-IR spectra of pure glimepiride is compared with those in FT-IR spectra of glimepiride with excipients as shown in Fig. 1. FT-IR spectral analysis indicated that the characteristic absorption peaks present in the IR spectra of glimepiride drug substance were also found in the physical mixtures of the polymers used (locust bean gum/gum ghatti/guar gum/microcrystalline cellulose) without any appreciable change in the position, attributing to the compatibility of drug-polymer. Hence, it can be concluded that drug can be used with the selected polymer without causing instability in the formulation.

\section{FT-IR studies of atorvastatin calcium}

The position of the peak in FT-IR spectra of pure atorvastatin calcium is compared with those in FT-IR spectra of atorvastatin calcium with excipients as shown in Fig. 2. FT-IR spectral analysis indicated that the characteristic absorption peaks present in the IR spectra of atorvastatin calcium drug substance were also found in the physical mixtures of the excipients used (microcrystalline cellulose/locust bean gum/sodium starch glycolate/croscarmellose sodium/sodium lauryl sulfate/sodium bicarbonate/PVP K-30) without any appreciable change in the position, attributing to the compatibility of drug-polymer. Hence, it can be concluded that drug can be used with the selected polymer without causing instability in the formulation.

\section{DSC studies of glimepiride}

As shown in Fig. 3, it was evident that glimepiride API DSC analysis shows a sharp endothermic peak at its melting point, i.e., at $207^{\circ} \mathrm{C}$, 


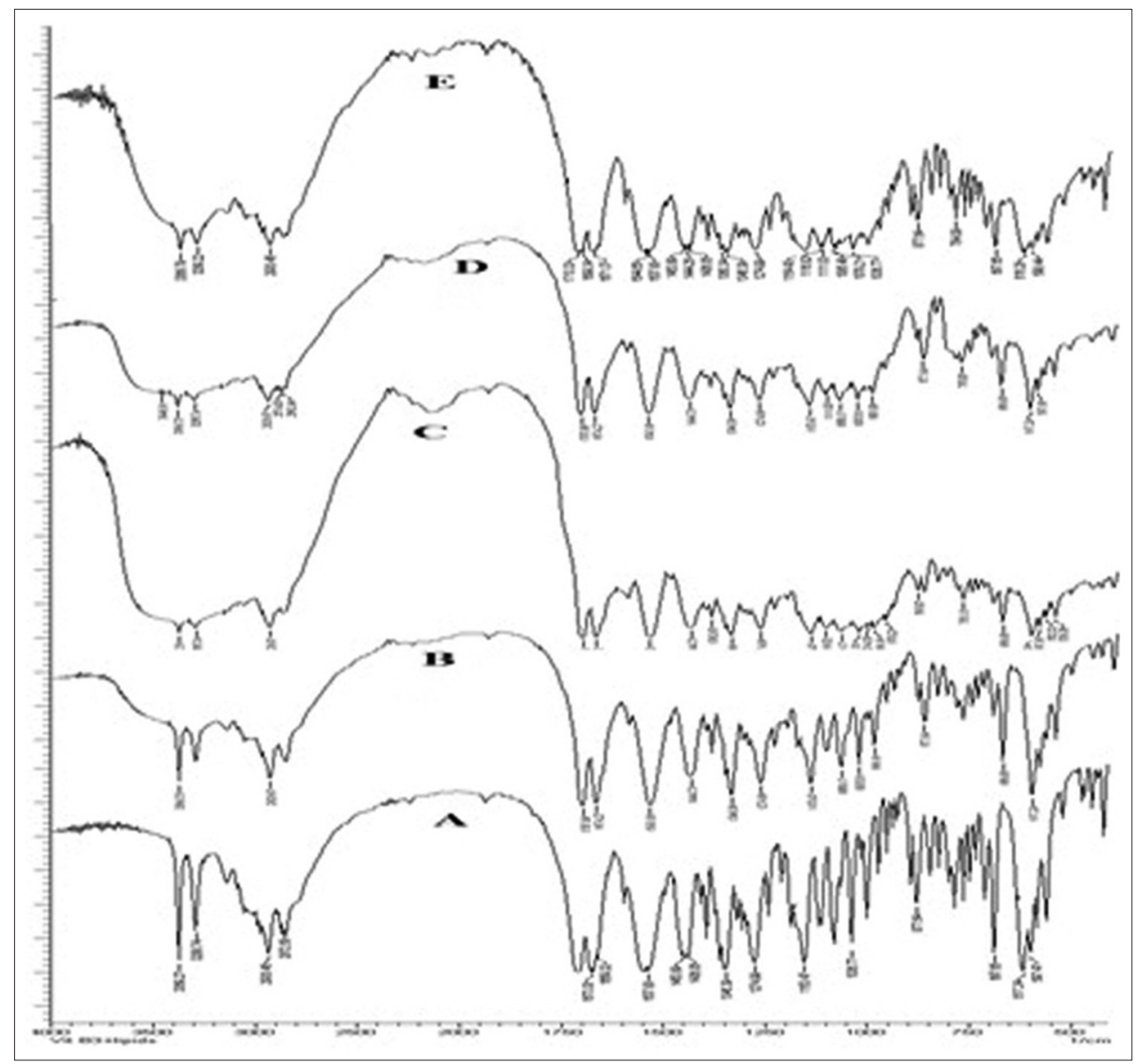

Fig. 1: Fourier transform infrared spectra of: (A) Glimepiride pure drug; (B) glimepiride+locust bean gum; (C) glimepiride+gum ghatti; (D) glimepiride+guar gum; (E) glimepiride+microcrystalline cellulose

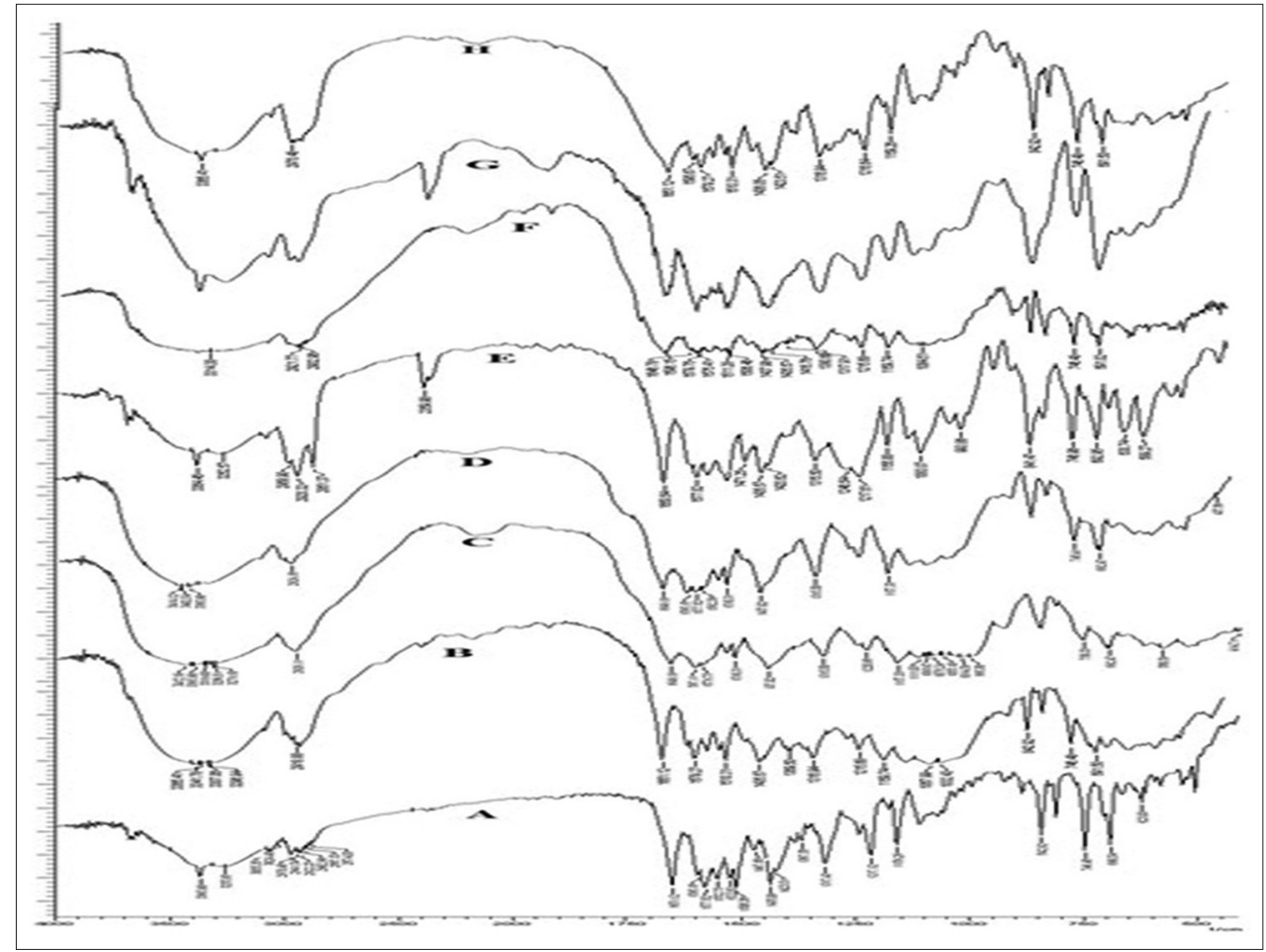

Fig. 2: Fourier transform infrared spectra of: (A) Atorvastatin calcium pure drug; (B) atorvastatin calcium+microcrystalline cellulose;

(C) atorvastatin calcium+sodium starch glycolate; (D) atorvastatin calcium+croscarmellose sodium; (E) atorvastatin calcium+sodium lauryl sulfate; (F) atorvastatin calcium+locust bean gum; (G) atorvastatin calcium+sodium bicarbonate; (H) atorvastatin calcium+PVP K-30 
indicating its crystalline nature of the drug. On the other hand, the DSC thermographs of formulation BD-2, BD-8, and BD-13 showed identical peaks to that of pure drug indicating the absence of chemical interaction between the drug and polymers.

\section{DSC studies of atorvastatin calcium}

The thermal analysis of pure atorvastatin calcium API showed a sharp endothermic peak at its melting point, i.e., at $156.87^{\circ} \mathrm{C}$, demonstrating its crystalline nature. On the other hand, identical but broad peaks were found on DSC analysis of formulations FR-7, FR-14, and FR-15, indicating no interaction of atorvastatin calcium with its polymers and excipients. DSC thermograms of atorvastatin calcium API formulations FR-7, FR-14, and FR-15 are shown in Fig. 4.

\section{Solubility}

The solubility of glimepiride was found to be $4.38,18.24$, and 24.09 g/L in $\mathrm{pH} 1.2,6.8$, and 7.2, respectively. Similarly, the solubility of atorvastatin calcium was found to be $6.84,214.67$, and $287.43 \mathrm{~g} / \mathrm{L}$ in pH 1.2, 6.8, and 7.2 phosphate buffers, respectively. From the results, it can be inferred that both glimepiride and atorvastatin calcium were more soluble in alkaline $\mathrm{pH}$, i.e., $>7$.

\section{pH of gums}

The locust bean gum is a non-ionic neutral polysaccharide and it reduces syneresis at a $\mathrm{pH}$ range of 5.6 $\pm 0.49 ; \mathrm{pH}$ of Guar gum obtained was $5.2 \pm 0.27$. Ghatti gum having a $\mathrm{pH}$ range of $4.7 \pm 0.51$ was favorable for the formulation of pellets.

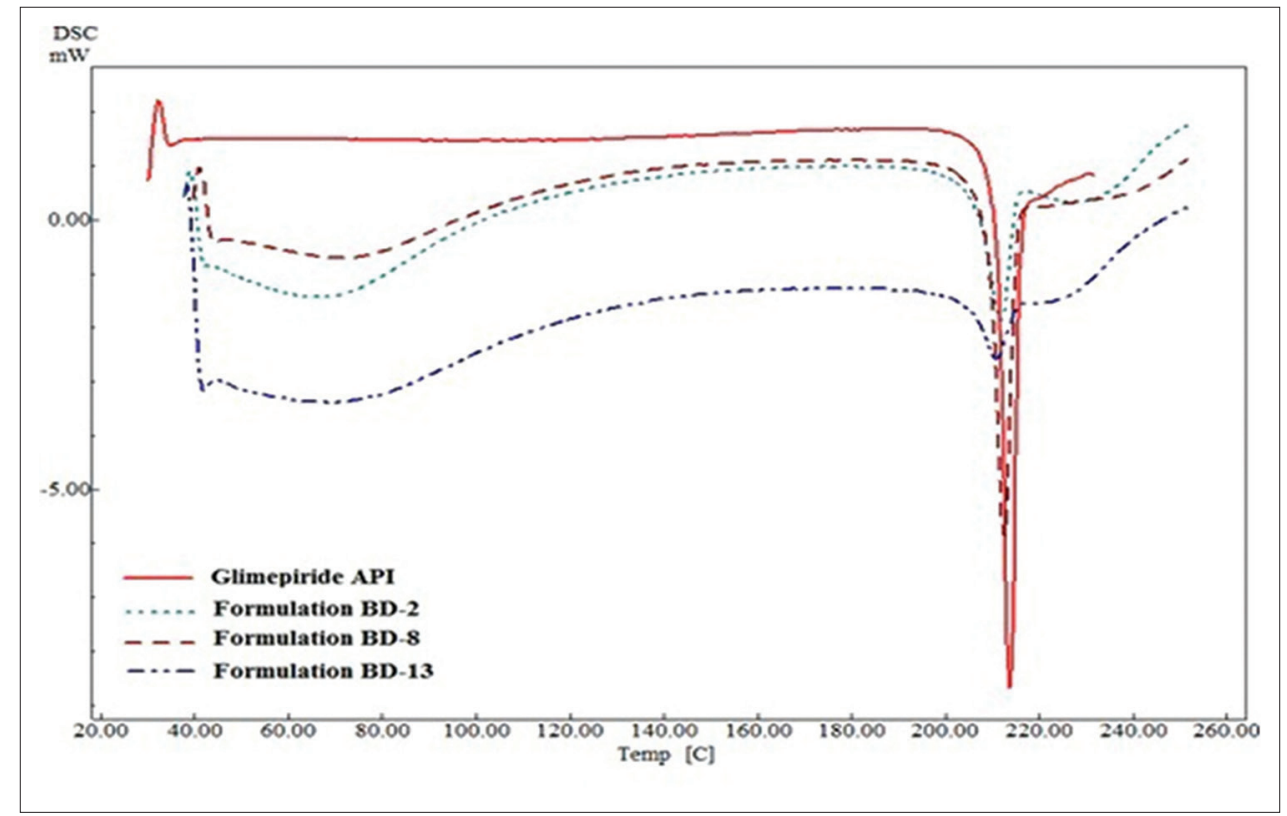

Fig. 3: Differential scanning calorimetry thermogram of glimepiride, formulation BD-2, BD-8, and BD-13

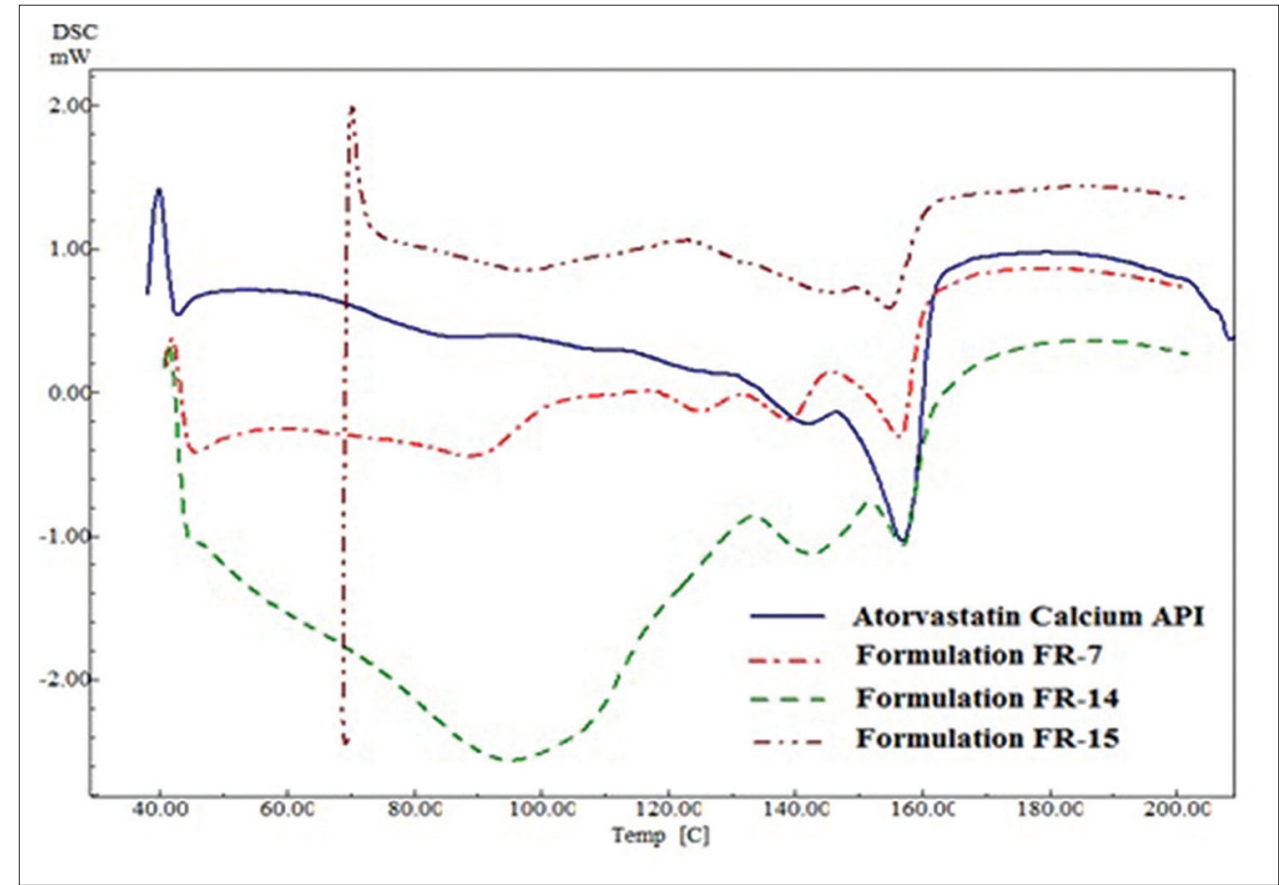

Fig. 4: Differential scanning calorimetry thermogram of atorvastatin calcium attention of pharmaceutical industries, formulation FR-7, FR-14, and FR-15 
SEM studies of glimepiride

From the SEM photograph as shown in Fig. 5, it was observed that the SR glimepiride pellets formulated using locust bean gum and gum ghatti/ guar gum polymers exhibited spherical shape. The pellets consisting of locust bean gum alone and locust bean gum with gum ghatti polymer were of the smoother surface, while pellets prepared using guar gum along with locust bean gum showed chapped surface.

\section{SEM studies of atorvastatin calcium}

From the SEM photograph as shown in Fig. 6, it was observed that the immediate release atorvastatin calcium pellets formulated using $1 \% \mathrm{w} / \mathrm{w}$ locust bean gum as a binder and sodium starch glycolate/ croscarmellose sodium exhibited spherical shape. The pellets consisting of locust bean gum and sodium starch glycolate were of the smoother surface, while pellets prepared using locust bean gum and croscarmellose sodium showed chapped surface.

\section{Micromeritic properties of glimepiride}

The micromeritic properties of different batches of SR glimepiride pellets are shown in Table 3. The properties such as average size (m), the angle of repose, tapped density, and Carr's index revealed no significant difference among all batches. The angle of repose of all batches ranged between $23.20 \pm 1.35$ and $27.35 \pm 1.58$ indicating good flow properties of pellets. The bulk density results of different batches of SR glimepiride pellets indicated close packing settlement due to the narrow particle size distribution.

Micromeritic properties of atorvastatin calcium

The micromeritic properties of different batches of immediate release atorvastatin calcium pellets are shown in Table 4. The properties such as average size $(\mathrm{mm})$, the angle of repose, tapped density, and Carr's index revealed no significant difference among all batches. The angle of repose of all batches ranged between $24.19 \pm 1.33$ and $27.46 \pm 1.37$ indicating good flow properties of pellets.

\section{Evaluation of pellets}

Friability and percentage yield glimepiride

The experimental results of the friability test and pellet yield of the SR glimepiride pellet formulations are summarized. The friability of the SR glimepiride pellet formulations were found to be in the range $0.32 \pm 0.08-0.53 \pm 0.07 \%$, and the results were in acceptable limits. The pellet yield was in the range of $76.9 \pm 2.31-83.3 \pm 3.16 \%$ in successive unit operations when $100 \mathrm{~g}$ of bulk material is being used.

\section{Friability and percentage yield atorvastatin pellets}

The experimental results of the friability test and pellet yield of the immediate release atorvastatin calcium pellet formulations are summarized. The friability of the immediate release atorvastatin calcium pellet formulations was found to be in the range $0.44 \pm 0.02-$ $0.54 \pm 0.05 \%$, and the results were in acceptable limits. The pellet yield was in the range of $74.8 \pm 1.21-82.4 \pm 1.49 \%$ in successive unit operations when $100 \mathrm{~g}$ of bulk material is being used.

\section{Drug loading and entrapment efficiency glimepiride}

The drug-loading percentage in the formulations was found to be within $2.28 \pm 0.23-2.55 \pm 0.15 \%$. The encapsulation percentage was found to be $85.40 \pm 1.21-95.51 \pm 1.23 \%$. From the results, it can be inferred that,
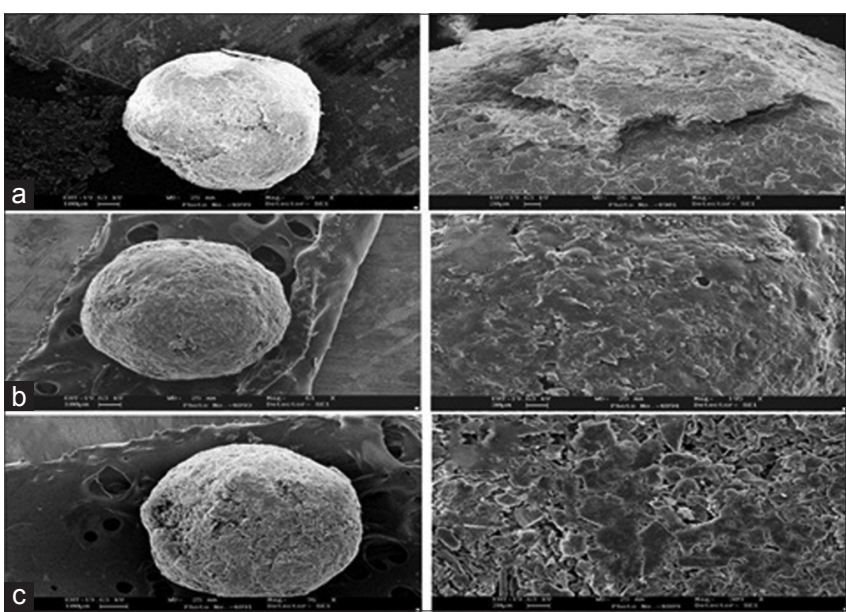

Fig. 5: Scanning electron microscopy of sustained release glimepiride pellets: (a) formulation BD-2; (b) formulation BD-8; and (c) formulation BD-13 at different magnifications
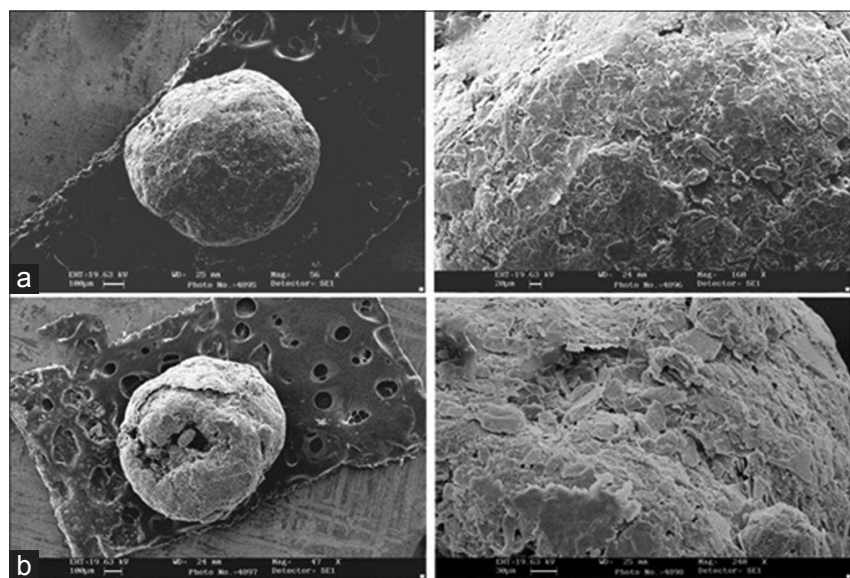

Fig 6: Scanning electron microscopy of immediate release atorvastatin calcium pellets: (a) formulation FR-7 and (b) formulation FR-14 at different magnification

Table 3: Characteristics of sustained release glimepiride pellets formulation

\begin{tabular}{|c|c|c|c|c|c|}
\hline $\begin{array}{l}\text { Formulation } \\
\text { code }\end{array}$ & $\begin{array}{l}\text { Average } \\
\text { size }(\mathbf{m m})^{*}\end{array}$ & $\begin{array}{l}\text { Angle of } \\
\text { repose } * * \theta^{\circ}\end{array}$ & $\begin{array}{l}\text { Granule } \\
\text { density }\left(\mathrm{g} / \mathrm{cm}^{3}\right)^{* *}\end{array}$ & $\begin{array}{l}\text { Tapped } \\
\text { density }\left(\mathrm{g} / \mathrm{cm}^{3}\right)^{* *}\end{array}$ & $\begin{array}{l}\text { Carr's } \\
\text { index }(\%)^{* *}\end{array}$ \\
\hline BD-1 & $1135 \pm 51$ & $25.14 \pm 1.24$ & $1.05 \pm 0.03$ & $0.84 \pm 0.04$ & $9.12 \pm 0.32$ \\
\hline BD-2 & $1189 \pm 25$ & $26.42 \pm 1.18$ & $1.03 \pm 0.04$ & $0.86 \pm 0.07$ & $8.79 \pm 0.24$ \\
\hline BD-3 & $1245 \pm 23$ & $25.45 \pm 1.26$ & $1.08 \pm 0.03$ & $0.90 \pm 0.03$ & $9.39 \pm 0.21$ \\
\hline BD-4 & $1224 \pm 35$ & $23.20 \pm 1.35$ & $1.05 \pm 0.02$ & $0.89 \pm 0.06$ & $8.93 \pm 0.34$ \\
\hline BD-5 & $1318 \pm 27$ & $27.21 \pm 1.30$ & $1.12 \pm 0.06$ & $0.83 \pm 0.05$ & $8.76 \pm 0.30$ \\
\hline BD-6 & $1336 \pm 32$ & $26.48 \pm 1.44$ & $1.04 \pm 0.08$ & $0.83 \pm 0.05$ & $8.69 \pm 0.37$ \\
\hline BD-8 & $1380 \pm 21$ & $26.65 \pm 1.88$ & $1.09 \pm 0.05$ & $0.90 \pm 0.03$ & $9.39 \pm 0.36$ \\
\hline BD-9 & $1262 \pm 73$ & $26.83 \pm 1.28$ & $1.08 \pm 0.06$ & $0.89 \pm 0.04$ & $8.93 \pm 0.29$ \\
\hline BD-10 & $1294 \pm 42$ & $26.25 \pm 1.36$ & $1.16 \pm 0.04$ & $0.83 \pm 0.05$ & $8.76 \pm 0.38$ \\
\hline BD-11 & $1359 \pm 32$ & $24.68 \pm 1.54$ & $1.02 \pm 0.03$ & $0.83 \pm 0.07$ & $8.69 \pm 0.41$ \\
\hline BD-12 & $1331 \pm 33$ & $25.66 \pm 1.15$ & $1.07 \pm 0.04$ & $0.84 \pm 0.06$ & $8.85 \pm 0.35$ \\
\hline BD-13 & $1397 \pm 23$ & $27.35 \pm 1.58$ & $1.05 \pm 0.02$ & $0.90 \pm 0.04$ & $9.39 \pm 0.44$ \\
\hline
\end{tabular}

$*$ mean $+\mathrm{SD}, \mathrm{n}=3, * *<0.05$ 
as polymer concentration increases, drug loading and encapsulation efficiency also increase. From the results, we can conclude that there

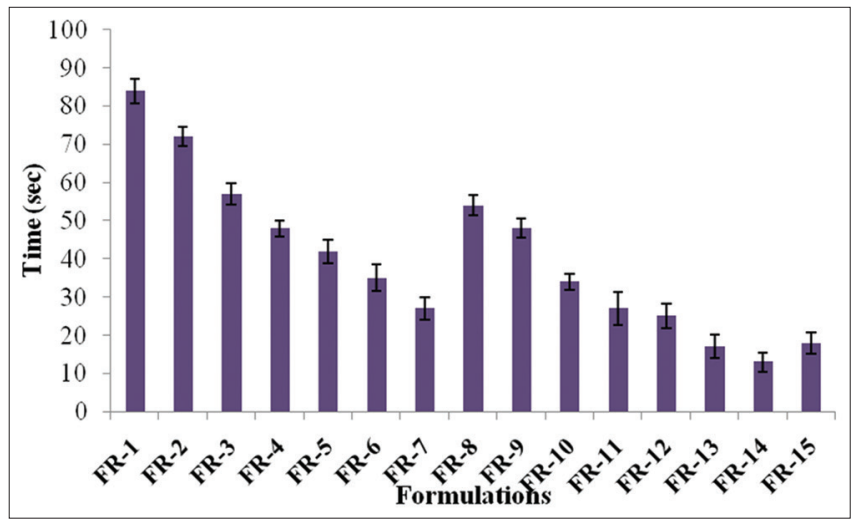

Fig. 7: Disintegration time of different formulations of immediate release atorvastatin calcium pellets is a proper distribution of glimepiride pellets and the deviations are in the acceptable limits.

Drug loading and encapsulation efficiency atorvastatin calcium The drug-loaded percentage in the formulation was found to be within $3.06 \pm 0.18-3.80 \pm 0.31 \%$. The encapsulation percentage was found to be $87.15 \pm 0.96-95.19 \pm 1.76 \%$. From the results, it can be inferred that there is a proper distribution of atorvastatin calcium in the pellets and the deviations are within the acceptable limits.

\section{Pellet disintegration time}

High disintegration time was observed for atorvastatin calcium pellets containing sodium starch glycolate as super disintegrant when compared to croscarmellose sodium. The results are mentioned graphically as shown in Fig. 7. The significant longer disintegration time for sodium starch glycolate containing pellets can be attributed to its disintegration mechanism, which acts by swelling on contact with the aqueous medium and further accompanied by gelling, which could possibly occlude the pores in the pellets prolonging further disintegration. Unlike sodium starch glycolate, the croscarmellose
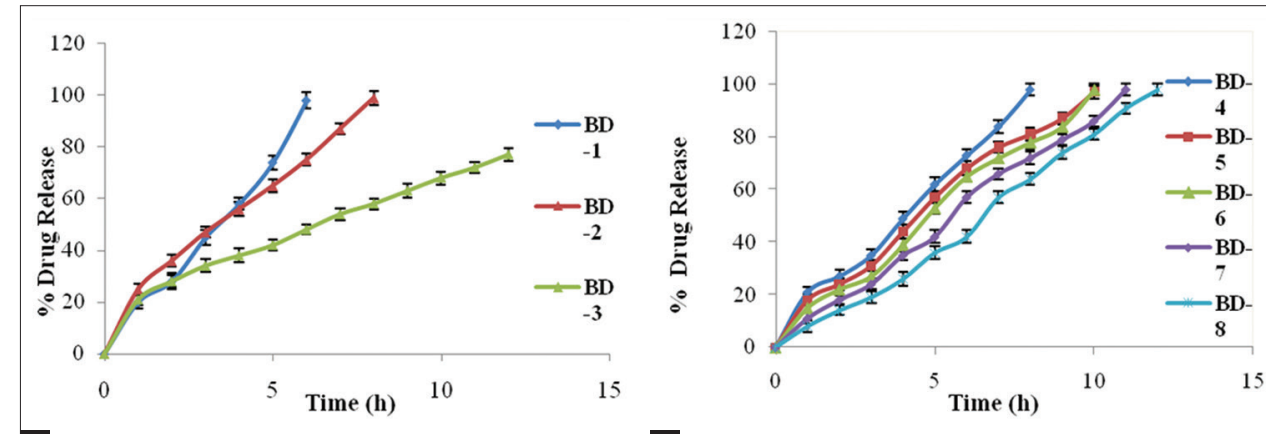

a

b

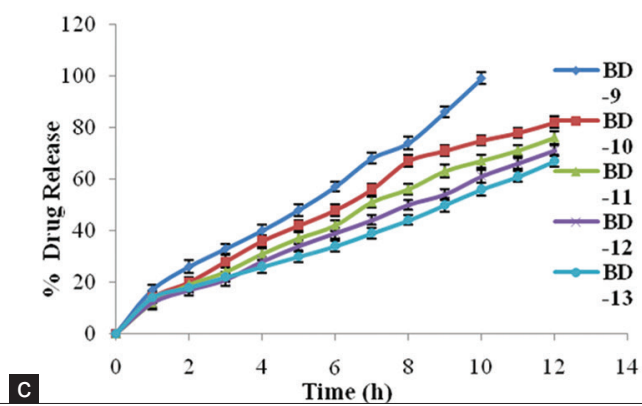

Fig. 8: (a-c) In vitro dissolution profile of sustained release glimepiride pellets

Table 4: Characteristics of immediate release atorvastatin calcium pellet formulations

\begin{tabular}{|c|c|c|c|c|c|}
\hline $\begin{array}{l}\text { Formulation } \\
\text { code }\end{array}$ & $\begin{array}{l}\text { Average } \\
\operatorname{size}^{*}(\mathrm{~mm})\end{array}$ & $\begin{array}{l}\text { Angle of } \\
\text { repose }^{* *} \theta^{\circ}\end{array}$ & $\begin{array}{l}\text { Granule } \\
\text { density** }\left(\mathrm{g} / \mathrm{cm}^{3}\right)\end{array}$ & $\begin{array}{l}\text { Tapped } \\
\text { density }^{* *}\left(\mathrm{~g} / \mathrm{cm}^{3}\right)\end{array}$ & $\begin{array}{l}\text { Carr's } \\
\text { index }^{* *}(\%)\end{array}$ \\
\hline FR-1 & $1127 \pm 41$ & $25.14 \pm 1.52$ & $1.09 \pm 0.04$ & $0.79 \pm 0.05$ & $8.11 \pm 0.42$ \\
\hline FR-2 & $1177 \pm 30$ & $26.42 \pm 1.24$ & $1.04 \pm 0.02$ & $0.81 \pm 0.04$ & $8.19 \pm 0.49$ \\
\hline FR-3 & $1255 \pm 43$ & $25.25 \pm 1.46$ & $1.07 \pm 0.08$ & $0.80 \pm 0.05$ & $9.21 \pm 0.44$ \\
\hline FR-4 & $1274 \pm 45$ & $24.19 \pm 1.33$ & $1.03 \pm 0.06$ & $0.75 \pm 0.05$ & $8.01 \pm 0.18$ \\
\hline FR-5 & $1371 \pm 50$ & $27.21 \pm 1.69$ & $1.05 \pm 0.04$ & $0.76 \pm 0.04$ & $8.24 \pm 0.80$ \\
\hline FR-6 & $1204 \pm 57$ & $26.18 \pm 1.27$ & $1.05 \pm 0.06$ & $0.83 \pm 0.03$ & $9.09 \pm 0.41$ \\
\hline FR-8 & $1208 \pm 32$ & $26.65 \pm 1.47$ & $1.06 \pm 0.05$ & $0.84 \pm 0.02$ & $8.54 \pm 0.54$ \\
\hline FR-9 & $1219 \pm 44$ & $26.55 \pm 1.24$ & $1.02 \pm 0.04$ & $0.81 \pm 0.04$ & $8.05 \pm 0.87$ \\
\hline FR-10 & $1244 \pm 37$ & $26.04 \pm 1.35$ & $1.07 \pm 0.06$ & $0.85 \pm 0.05$ & $8.46 \pm 1.03$ \\
\hline FR-11 & $1247 \pm 42$ & $24.54 \pm 1.42$ & $1.01 \pm 0.05$ & $0.79 \pm 0.02$ & $8.21 \pm 1.13$ \\
\hline FR-12 & $1265 \pm 47$ & $27.46 \pm 1.37$ & $1.05 \pm 0.04$ & $0.81 \pm 0.05$ & $8.48 \pm 0.14$ \\
\hline FR-13 & $1341 \pm 34$ & $26.35 \pm 1.41$ & $1.08 \pm 0.03$ & $0.80 \pm 0.05$ & $9.04 \pm 0.22$ \\
\hline FR-14 & $1280 \pm 29$ & $26.41 \pm 1.35$ & $1.07 \pm 0.04$ & $0.82 \pm 0.03$ & $8.47 \pm 0.27$ \\
\hline FR-15 & $1318 \pm 36$ & $27.11 \pm 1.32$ & $1.04 \pm 0.05$ & $0.81 \pm 0.06$ & $8.21 \pm 0.60$ \\
\hline
\end{tabular}

$*$ mean \pm SD, $n=3,{ }^{* *}<0.05$ 


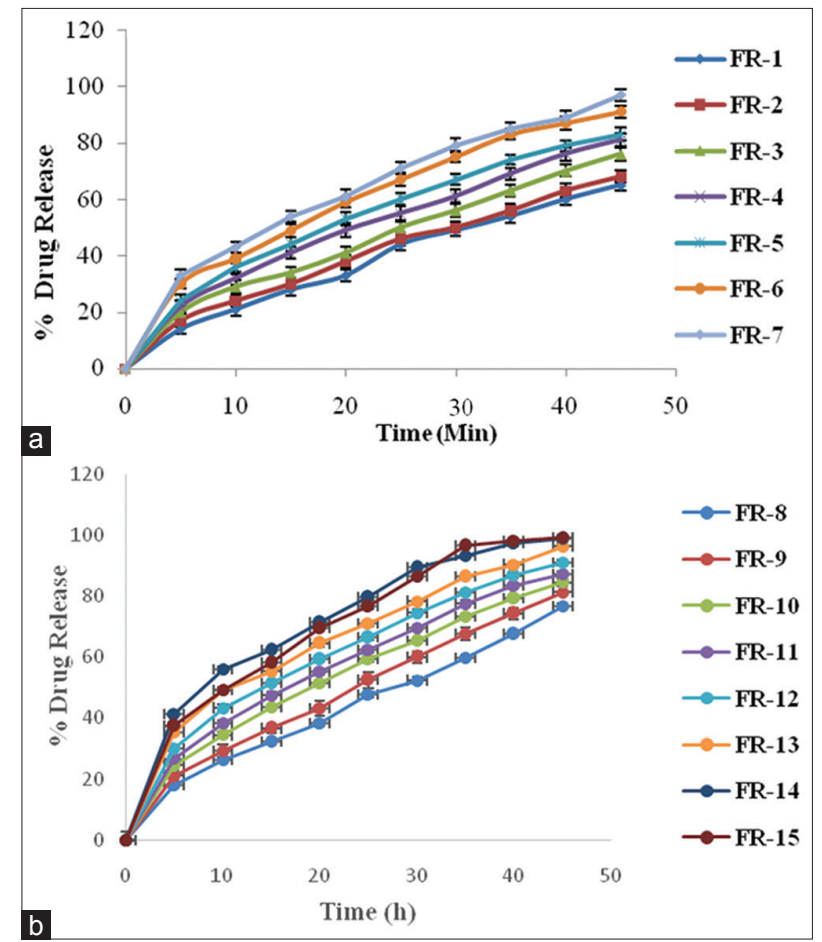

Fig. 9: ( $a$ and b) In vitro dissolution profile of Atorvastatin calcium pellets sodium has a dual functional mechanism of disintegration, i.e., water wicking and rapid swelling, leading to superior disintegration characteristics than sodium starch glycolate, which is the rate-limiting step for dissolution of the drug.

In vitro dissolution studies of SR GLIMEPIRIDE and immediate release atorvastatin calcium pellets in FDC

Various formulations of SR glimepiride and immediate release atorvastatin calcium were evaluated for the in vitro study as shown in Figs. 8a-c and 9a and b. Among all the formulations of SR glimepiride pellets, BD-8 had sustained the drug release up to $12 \mathrm{~h}$. Among all the formulations of immediate release atorvastatin calcium pellets, FR-14 was considered to be optimized because it shows faster drug release of $89.32 \pm 2.4 \%$ which contains $1 \%$ locust bean and $7 \% \mathrm{w} / \mathrm{v}$ croscarmellose sodium.

In vivo studies of SR glimepiride and immediate release atorvastatin calcium pellets in FDC

A comparative plasma profile was performed between both Glimepiride and Atorvastatin API and its respective optimized formulations BD-8 and FR-14. As shown in Table 5 and Fig. 10, the results show that formulation BD-8 was found to be more significant than glimepiride API with respect to bioavailability and the formulation FR-14 was found to be more significant than atorvastatin API with respect to relative bioavailability. Table 6 summarizes the pharmacokinetic parameters of FDC of glimepiride API with atorvastatin calcium API and of the optimized SR glimepiride pellet formulation (BD-8) with optimized immediate release atorvastatin calcium pellet formulation (FR-14).

Table 5: Plasma profile of sustained release glimepiride and immediate release atorvastatin pellets

\begin{tabular}{lllll}
\hline \multirow{2}{*}{ Time (h) } & \multicolumn{4}{l}{ Plasma drug concentration $\mathbf{( n g} / \mathbf{m l}$ )* } \\
\cline { 2 - 5 } & Glimepiride API & Formulation BD 8 & Atorvastatin calcium API & Formulation FR 14 \\
\hline 0.5 & $0786.2 \pm 134.18$ & $0319.21 \pm 112.14$ & $138.21 \pm 40.53$ & $383.16 \pm 73.11$ \\
1.0 & $1123.10 \pm 170.24$ & $0433.32 \pm 148.49$ & $348.02 \pm 66.07$ & $614.03 \pm 91.44$ \\
1.5 & $1435.60 \pm 184.5$ & $0653.58 \pm 173.53$ & $316.33 \pm 63.34$ & $573.88 \pm 84.32$ \\
2.0 & $1847.20 \pm 210.14$ & $0967.30 \pm 193.66$ & $299.28 \pm 51.76$ & $494.90 \pm 73.41$ \\
3.0 & $2238.80 \pm 220.79$ & $1276.37 \pm 207.18$ & $263.67 \pm 59.29$ & $433.67 \pm 68.37$ \\
4.0 & $3219.52 \pm 286.34$ & $1655.53 \pm 229.04$ & $227.39 \pm 61.51$ & $315.21 \pm 59.65$ \\
6.0 & $1862.67 \pm 178.79$ & $1883.20 \pm 267.39$ & $186.20 \pm 34.40$ & $234.01 \pm 66.51$ \\
8.0 & $862.21 \pm 127.26$ & $1534.19 \pm 193.91$ & $139.16 \pm 29.16$ & $167.44 \pm 38.14$ \\
10.0 & $393.05 \pm 83.70$ & $1243.11 \pm 177.83$ & $112.53 \pm 31.26$ & $121.36 \pm 35.32$ \\
12.0 & $26.44 \pm 14.15$ & $864.35 \pm 164.40$ & $84.30 \pm 27.33$ & $90.21 \pm 31.40$ \\
24.0 & $9.13 \pm 3.83$ & $367.54 \pm 8.64$ & $6.09 \pm 3.32$ & $8.61 \pm 5.86$ \\
\hline
\end{tabular}

${ }^{*}$ mean \pm SD, n=3, API: Attention of pharmaceutical industries

Table 6: Summary of pharmacokinetic parameter after oral administration of glimepiride API and atorvastatin calcium API in FDC and also their respective optimized formulation, i.e., formulation BD-8 and Formulation FR-14 in FDC to rat

\begin{tabular}{lllllll}
\hline Parameters & $\mathbf{C}_{\max }(\mathbf{n g} / \mathbf{m L})$ & $\mathbf{T}_{\max }(\mathbf{h})$ & $\mathbf{t}_{\mathbf{1} / \mathbf{2}} \mathbf{( h )}$ & $\mathbf{K}_{\mathbf{e t}}\left(\mathbf{h}^{-1}\right)$ & $\left.\mathbf{A U C}_{\mathbf{0}-\mathbf{2} \mathbf{h}} \mathbf{( n g} / \mathbf{m L}\right)$ & $\mathbf{A U C} \mathbf{0}_{\mathbf{0}-\infty}(\mathbf{n g} / \mathbf{m L})$ \\
\hline Glimepiride API & $3219.52 \pm 286.36$ & $4.0 \pm 0$ & $2.28 \pm 0.11$ & $0.3053 \pm 0.019$ & $9689.1 \pm 87.3$ & $9718.47 \pm 45.2$ \\
Formulation BD-8 & $1883.20 \pm 267.39$ & $6.0 \pm 0$ & $7.72 \pm 0.15$ & $0.0898 \pm 0.0024$ & $15687.2 \pm 103.7$ & $19771.07 \pm 34.4$ \\
Atorvastatin calcium API & $348.02 \pm 66.27$ & $1.0 \pm 0$ & $4.08 \pm 0.17$ & $0.1695 \pm 0.021$ & $2570.5 \pm 97.5$ & $2606.14 \pm 64.6$ \\
Formulation FR-14 & $614.03 \pm 91.24$ & $1.0 \pm 0$ & $3.72 \pm 0.19$ & $0.1859 \pm 0.026$ & $3438.1 \pm 88.3$ & $3481.01 \pm 73.3$ \\
\hline
\end{tabular}

FDC: Fixed-dose combinations, API: Attention of pharmaceutical industries, ${ }^{*}$ mean \pm SD, $n=3$

Table 7: Stability studies of glimepiride sustained release and atorvastatin immediate release fixed-dose combination of BD-8 and FR-14 formulation

\begin{tabular}{|c|c|c|c|c|c|c|c|c|c|}
\hline \multirow{3}{*}{$\begin{array}{l}\text { Sampling } \\
\text { interval }\end{array}$} & \multicolumn{3}{|c|}{$25 \pm 2^{\circ} \mathrm{C} / 60 \pm 5 \% \mathrm{RH}$} & \multicolumn{3}{|c|}{$30 \pm 2^{\circ} \mathrm{C} / 65 \pm 5 \% \mathrm{RH}$} & \multicolumn{3}{|c|}{$40 \pm 2^{\circ} \mathrm{C} / 75 \pm 5 \%$} \\
\hline & \multirow[t]{2}{*}{ Friability } & \multicolumn{2}{|c|}{ Drug content (\%) } & \multirow[t]{2}{*}{ Friability } & \multicolumn{2}{|c|}{ Drug content (\%) } & \multirow[t]{2}{*}{ Friability } & \multicolumn{2}{|c|}{ Drug content $(\%)$} \\
\hline & & BD 7 & FR 14 & & BD 7 & FR 14 & & BD 7 & FR 14 \\
\hline 0 & $0.39 \pm 0.41$ & $98.7 \pm 0.20$ & $99.1 \pm 0.53$ & $0.37 \pm 0.41$ & $99.04 \pm 0.35$ & $98.71 \pm 0.80$ & $0.37 \pm 0.84$ & $98.14 \pm 0.49$ & $99.14 \pm 0.30$ \\
\hline 3 & $0.44 \pm 0.23$ & $99.2 \pm 0.18$ & $98.5 \pm 0.84$ & $0.47 \pm 0.73$ & $98.56 \pm 0.06$ & $98.53 \pm 0.22$ & $0.56 \pm 0.51$ & $99.33 \pm 0.66$ & $97.89 \pm 0.71$ \\
\hline 6 & $0.51 \pm 0.66$ & $98.0 \pm 0.73$ & $97.9 \pm 0.67$ & $0.54 \pm 0.16$ & $98.88 \pm 0.10$ & $07.95 \pm 0.51$ & $0.64 \pm 0.90$ & $99.61 \pm 0.18$ & $98.38 \pm 0.65$ \\
\hline
\end{tabular}




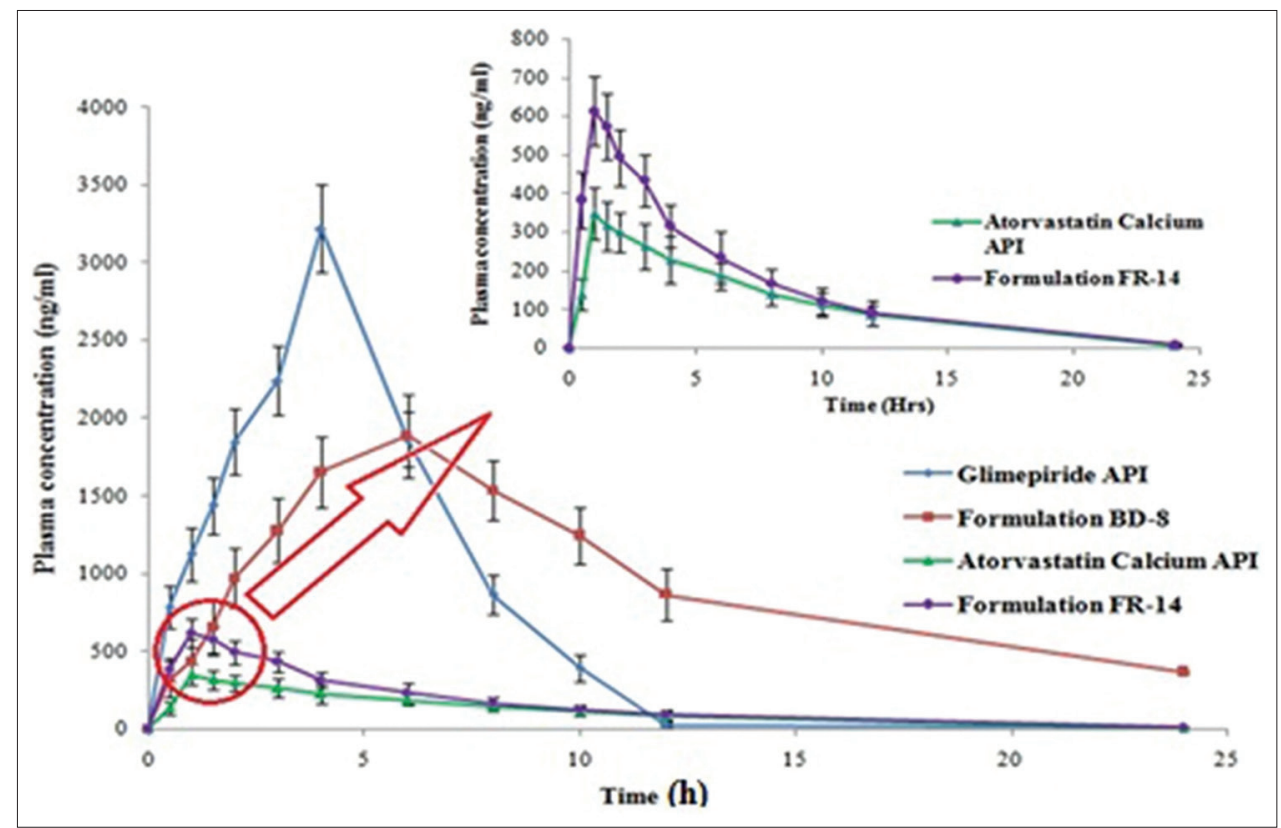

Fig. 10: Plasma drug concentration versus time profile of optimized formulations and their respective attention of pharmaceutical industries

\section{Stability studies}

Stability studies of FDC formulation of SR glimepiride formulation (BD-8) and immediate release atorvastatin formulation (FR-14) pellets were carried out at various temperature and humidity such as $25 \pm 2^{\circ} \mathrm{C} / 60 \pm 5 \%, 30 \pm 2^{\circ} \mathrm{C} / 65 \pm 5 \% \mathrm{RH}$, and $40 \pm 2^{\circ} \mathrm{C} / 75 \pm 5 \% \mathrm{RH}$. Formulations were subjected to various evaluation parameters. The results are shown in Table 7. From the results, it can be confirmed that there were no significant changes in physicochemical properties of the SR glimepiride formulation (BD-8) and immediate release atorvastatin formulation FR-14.

\section{CONCLUSION}

There is a strong prophylactic and clinical need to develop novel fixed combination delivery systems for improvement of glucose tolerance in type II diabetes patients associated with dyslipidemia with desired characteristics such as better therapeutic efficacy, convenience, reduced pill burden, and simplified administration of regiments with cost-effective medication. The developed fixed-dose, combination dosage forms, namely MUPS, have demonstrated its superiority in the improvement of metabolic disorders. Thus, the study demonstrates that the developed FDC systems have a great appeal for the convenient treatment of diabetic dyslipidemia that may be explored in improving the limitation of existing monotherapy drug delivery systems.

\section{ACKNOWLEDGMENTS}

The authors express their gratitude to the JSS Academy of Higher Education and Research and JSS College of Pharmacy, Mysuru, for providing necessary support in due course of the work.

\section{AUTHORS' CONTRIBUTIONS}

The author is a faculty in division of pharmaceutics and the work, and the work contributed on faculty development program in the institution. All the authors discussed the results and contributed to the final manuscript.

\section{CONFLICTS OF INTEREST}

The author confirms that this article content has no conflicts of interest.

\section{REFERENCES}

1. Scheen AJ. Drug treatment of non-insulin-dependent diabetes mellitus in the 1990s. Drugs 1997;54:355-68.

2. Zhang X, Cui X, Li F, Wang S, Liu X, Hui L, et al. Association between diabetes mellitus with metabolic syndrome and diabetic microangiopathy. Exp Ther Med 2014;8:1867-73.

3. Bhad ME, Abdul S, Jaiswal SB, Chandewar AV, Jain JM, Sakarkar DM. MUPS tablets a brief review. Int J Pharm Tech Res 2010;2:847-55.

4. Altuntas TG, Erk N. Liquid chromatographic determination of atorvastatin in bulk drug, tablets, and human plasma. J Liq Chromatogr Relat Technol 2004;27:83-93.

5. Inukai K, Watanabe M, Nakashima Y, Sawa T, Takata N, Tanaka M, et al. Efficacy of glimepiride in Japanese Type 2 diabetic subjects. Diabetes Res Clin Pract 2005;68:250-7.

6. Ho JE, Paultre F, Mosca L. Is diabetes mellitus a cardiovascular disease risk equivalent for fatal stroke in women? Data from the women's pooling project. Stroke 2003;34:2812-6.

7. Patel SA, Patel NG, Joshi AB. Multiple unit pellet system (MUPS) based fast disintegrating delayed-release tablets for pantoprazole delivery. Int J Pharm Pharm Sci 2018;10:77-84.

8. Higuchi TK. A phase solubility technique. Adv Anal Chem Instrum 1965;4:117-211.

9. Clarke GM, Newton JM, Short MB. Comparative gastrointestinal transit of pellet systems of varying density. Int J Pharm 1995;114:1.

10. Rojas J, Correa D. Comparative evaluation of the release properties of verapamil hcl and carbamazepine from microcrystalline cellulose II pellets. Int J Pharm Pharm Sci 2017;9:182-6.

11. Kilor VA, Sapkal NP, Awari JG, Shewale BD. Development and characterization of enteric-coated immediate-release pellets of aceclofenac by extrusion/spheronization technique using $\kappa$-carrageenan as a pelletizing agent. AAPS PharmSciTech 2010;11:336-43.

12. Bechard SR, Leroux JC. Coated pelletized dosage form: Effect of compaction on drug release. Drug Dev Ind Pharm 1992;18:1927-44.

13. Dash SK, Khan AS, Das SR, Padhan A, Rout D, Behera BC. Formulation and in-vitro evaluation of sustained released glibenclamide microspheres. Int J Pharm Sci Res 2012;3:1433.

14. Reddy GL. Development and in vitro-in vivo evaluation of extendedrelease multiple-unit pellet system tablets of metoprolol succinate. Asian J Pharm 2016;10:S39-42.

15. Arunkumar N, Deecaraman M, Rani C, Mohanraj KP, Venkateskumar K. Formulation development and in vitro evaluation of nanosuspensions loaded with atorvastatin calcium. Asian J Pharm 2014;23;4:28-33. 